\title{
Towards an optimal integrated reservoir system management for the Awash River Basin, Ethiopia
}

\author{
Ruben Müller, Henok Y. Gebretsadik, and Niels Schütze \\ Department of Hydrology, Technische Universität Dresden, Dresden, 01069, Germany \\ Correspondence to: Ruben Müller (ruben.mueller@tu-dresden.de)
}

Published: 12 May 2016

\begin{abstract}
Recently, the Kessem-Tendaho project is completed to bring about socioeconomic development and growth in the Awash River Basin, Ethiopia. To support reservoir Koka, two new reservoirs where built together with extensive infrastructure for new irrigation projects. For best possible socioeconomic benefits under conflicting management goals, like energy production at three hydropower stations and basin wide water supply at various sites, an integrated reservoir system management is required. To satisfy the multi-purpose nature of the reservoir system, multi-objective parameterization-simulation-optimization model is applied. Different Paretooptimal trade-off solutions between water supply and hydro-power generation are provided for two scenarios (i) recent conditions and (ii) future planned increases for Tendaho and Upper Awash Irrigation projects. Reservoir performance is further assessed under (i) rule curves with a high degree of freedom - this allows for best performance, but may result in rules curves to variable for real word operation and (ii) smooth rule curves, obtained by artificial neuronal networks. The results show no performance penalty for smooth rule curves under future conditions but a notable penalty under recent conditions.
\end{abstract}

\section{Introduction}

Recently, the Kessem-Tendaho Project is completed to bring about socioeconomic development and growth in the Awash River Basin, Ethiopia. To support the existing Koka reservoir two new reservoirs where built together with extensive infrastructure for new irrigation projects. Besides the basin wide supply of water of municipal water, irrigation water for various agricultural sites and sugar cane plantations, the reservoirs are also responsible for flood protection. Hydropower production is a critical factor for the local economy. Koka reservoir provides hydropower through hydropower station Awash I and supports the hydro-power stations Awash II and III. Development plans project an increase of 40000 ha in Tendaho Irrigation project and expansion of upper Awash irrigation site by two fold.

For maximum socioeconomic gains an integrated reservoir system management is crucial. To achieve this, optimal operational policies for all reservoirs are needed. Mathematical optimization models are used widely in water resources management to provide operational policies for optimal integrated reservoir management (Loucks et al., 1981).
To account for multi-purpose nature of the Awash River Basin reservoir system a multi-objective parameterizationsimulation-optimization (PSO) model is developed in this study. In PSO a reservoir management simulation model is coupled to an optimization algorithm to iteratively search for better operational policies. The advantages of PSO over other common optimization techniques are discussed in Koutsoyiannis and Economou (2003).

Yibetal et al. (2013) analysed the water audit of Awash Basin using WEAP model on the basis of three different scenarios (Expansion of irrigation area, improvement of irrigation and Climate change). Berhe et al. (2013) assessed the water allocation for future development scenarios in a modelling study using MODSIM model (Labadie, 2007). However hydropower production is modelled on purely opportunistic basis, because releases from the reservoir respond only to irrigation demands.

This study is a first step to provide optimal rule curves for an integrated management of the reservoir system for possible compromises between energy production and basin wide water supply for (i) recent conditions and (ii) the planned in- 


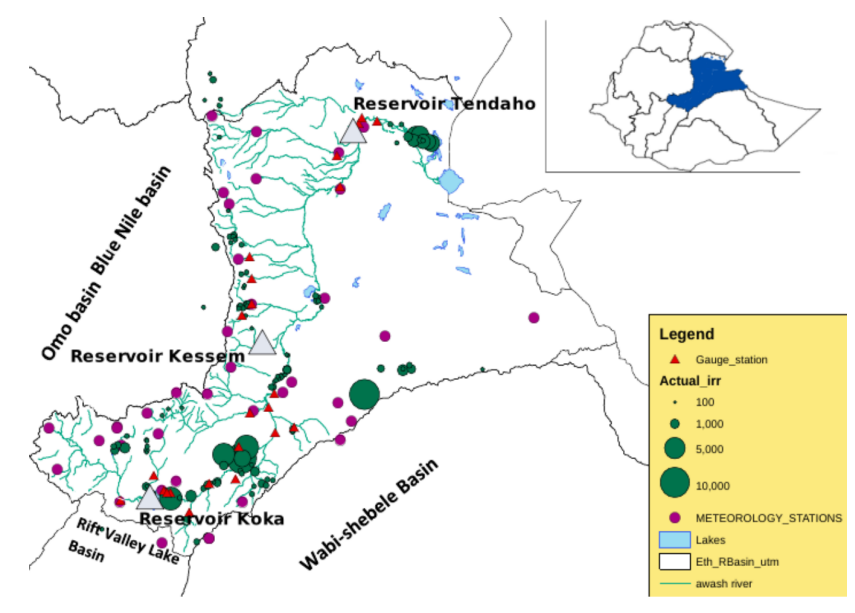

Figure 1. Map of Awash River Basin, highlighting the reservoir system and the local irrigation projects (adopted from Gebretsadik, 2015).

crease of 40000 ha in Tendaho Irrigation project and expansion of upper Awash irrigation site by two fold. Sustainability is assessed in two steps. The maximum performance of the reservoir system is assessed with curves with a high degree of freedom. This allows for best performance, but results in non-smooth monthly rule curves which are not favoured by reservoir operators. Therefore also smoothness constrained rule curves are optimized by using a surrogate function. Possible losses of reservoir system performance are analysed.

The Awash River originates from a high plateau, which is the central Ethiopian Highland and an elevation up to $3000 \mathrm{~m}$ a.s.l. It descends in the Rift Valley after passing Koka Reservoir and flows into Lake Abe near the border of Ethiopia at $250 \mathrm{~m}$ a.s.l. (see Fig. 1).

\section{Material and methods}

\subsection{Awash River Basin}

Awash River basin is one of the twelve basins in Ethiopia. The basin has a total catchment area of $110000 \mathrm{~km}^{2}$ and total length of $1200 \mathrm{~km}$.

Awash River has 15 important tributaries which significantly contribute for the flow of the main course.

The land use is dominated by exposed rock with about $34.9 \%$ followed by cultivated land of about $27 \%$ and open shrub land $(20.9 \%)$. The seasonal distribution of rainfall with two distinct rainy periods is caused by a shifting of the Inter Tropical Convergence Zone. The March-May season is the main rainfall season yielding $100-200 \mathrm{~mm}$ per month, followed by a lesser rainfall season in October-December with $100 \mathrm{~mm}$ per month. More detail about the basin give Berhe et al. (2013).
Table 1. Management zones and total storage in $10^{6} \mathrm{~m}^{3},\left({ }^{\mathrm{a}}\right)$ denotes upper constraints and $\left({ }^{b}\right)$ denotes lower constraints.

\begin{tabular}{lrrrr}
\hline Reservoir & Dead & Buffer & Conservation & Total \\
\hline Koka & 8 & $300^{\mathrm{b}}$ & $1000^{\mathrm{a}}$ & 1186 \\
Kessem & 200 & $200^{\mathrm{b}}$ & $500^{\mathrm{a}}$ & 800 \\
Tendaho & 364 & $364.6^{\mathrm{b}}$ & $1610^{\mathrm{a}}$ & 1860 \\
\hline
\end{tabular}

\subsection{Setup of the parameterization-simulation-optimization model}

For all reservoirs upper rule curves define the top of conservation storage zones and lower rule curves define the top of buffer storage zones. Important reservoir characteristics are summarized in Table 1. These storages mark upper and lower constraints in the optimization as the task is, to find optimal monthly storage values for each zone. Storage above the conservation zone is designated for flood protection.

Awash I hydropower station, located at Koka reservoir houses three units with 14.4 MW capacity. Average and firm production of hydropower are 110 and $80 \mathrm{GWh}$ per annum respectively. Awash II and Awash III run-of-river hydropower stations are located 25 and $28 \mathrm{~km}$ of the Koka dam. Both stations feature an installed capacity of $34 \mathrm{MW}$.

The regulated turbine flow is restricted to $40 \mathrm{~m}^{3} \mathrm{~s}^{-1}$. Reservoir Koka serves water for energy production only from the conservation zone; water in the buffer zone is preserved for supply of irrigation and municipal demands. Several problems arise from an unsatisfactory data basis. Almost no data is available to model the hydrological characteristics of the Gedabbesa swamp, which has high influence in the water allocation (Berhe et al., 2013).

Therefore, Gedabbesa swamp is modelled as follows: average monthly patterns for losses to the swamp and returns from the swamp are calculated from gauging stations upstream and downstream of the swamp. In the model all flow exists at node 702 and the difference between the monthly pattern of losses and the flow to node 702 is returned at node 703. Additional mean monthly returns enter at node 701. Similarly, little data is available for Lake Abe, the terminal lake of Awash River.

Awash I hydropower station, located at Koka reservoir houses three units with 14.4 MW capacity. Average and firm production of hydropower are $110 \mathrm{GWh}$ per annum and $80 \mathrm{GWh}$ per annum respectively. Awash II and Awash III run-of-river hydropower stations are located 25 and $28 \mathrm{~km}$ of the Koka dam. Both stations feature an installed capacity of $34 \mathrm{MW}$. The regulated turbine flow is restricted to $40 \mathrm{~m}^{3} \mathrm{~s}^{-1}$. Reservoir Koka serves water for energy production only from the conservation zone; water in the buffer zone is preserved for supply of irrigation and municipal demands. 


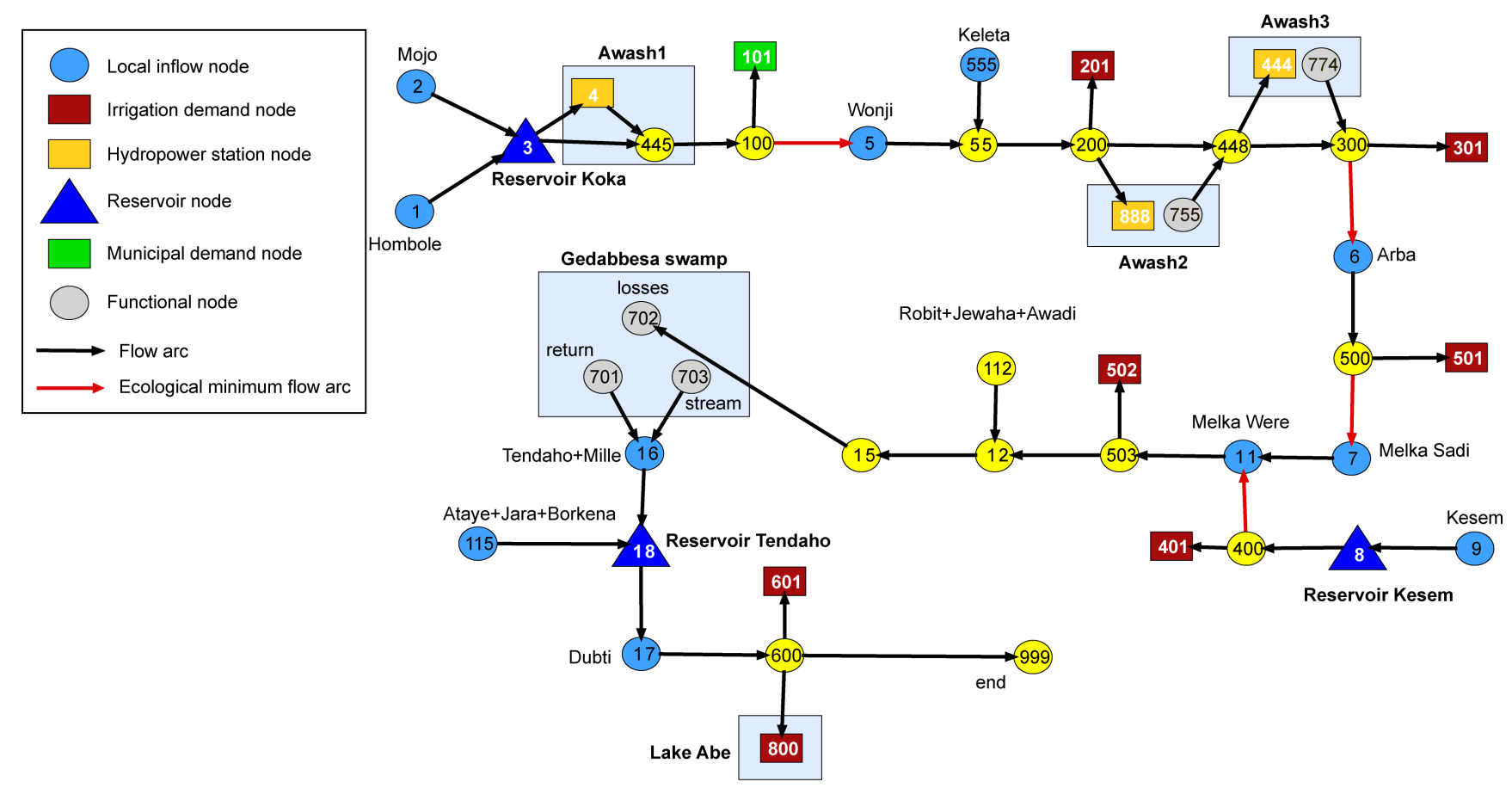

Figure 2. Schematic representation of Awash Basin multi-reservoir system in the modelling software OASIS.

\section{Formulation of the optimization problem}

The competing management goals of water supply for irrigation projects, municipal, ecology and the production of hydropower in the Awash river basin requires the formulation of two objective functions. Objective function $F_{1}$ minimizes the sum of all deficits over all demands

$\min \left(F_{1}\right)=\min \left\{\sum_{t=1}^{240}\left(D_{\mathrm{Mun}, t}+D_{\mathrm{Irr}, t}+D_{\mathrm{Eco}, t}\right)\right\}$,

where for each time step $t, D_{\mathrm{Irr}, t}$ is the sum of all deficits in the supply for all irrigation projects, $D_{\mathrm{Mun}, t}$ is the deficit in municipal supply and $D_{\mathrm{Eco}, t}$ is the sum of all deficits in ecological minimum flow support for all nodes as given in Fig. 2. Objective function $F_{2}$ maximizes the energy production of the three hydropower stations in the basin

$\max \left(F_{2}\right)=-1 \cdot \min$

$$
\cdot\left\{\sum_{t=1}^{240}\left(-E_{\text {Awash } 1, t}-E_{\text {Awash } 2, t}-E_{\text {Awash } 3, t}\right)\right\},
$$

where $E_{\mathrm{Awash} 1, t}$ is the energy production at hydropower unit Awash1 and $E_{\text {Awash2, } t}$ and $E_{\text {Awash3, } t}$ at units Awash2 and Awash3, respectively. The produced energy is calculated as $E=\eta g \rho Q_{\mathrm{T}} H(\mathrm{MWh})$, with efficiency of $\eta=0.9(-)$ for all units, turbine flows $Q_{\mathrm{T}}\left(\mathrm{m}^{3} \mathrm{~s}^{-1}\right)$ for all units is given by OASIS model, as is the head $H(\mathrm{~m})$ for Awash1. For Awash2 and Awash 3 run of river units the head is fixed at $60 \mathrm{~m}$.

Three models are considered, which vary in the formulation of the rule curves. In model MOD1 the lower rule curve of reservoir Koka is kept constant. For model MOD2 this lower rule is seasonally variable. Decision variables for MOD1 and MOD2 are the storage control volumes. A constraint free formulation and bounded formulation from Müller (2014) is used for MOD1 and MOD2. Smooth variable rule curves for MOD3 are obtained by formulating the rule curves as an artificial neuronal network

$$
\begin{aligned}
& Z_{s}^{k}=\alpha_{1, k}+\sum_{n=1}^{2} \cdot\left\{\alpha _ { 2 , k \cdot n } \cdot \operatorname { t a n s i g } \left(\alpha_{3, k \cdot n} \cdot \sin (T)\right.\right. \\
& \left.\left.\quad+\alpha_{4, k \cdot n} \cdot \cos (T)+\alpha_{5, k \cdot n}\right)\right\}, \\
& \quad \forall(s=1, \ldots, 12 ; k=1, \ldots, 4)
\end{aligned}
$$

subject to $Z^{\text {buffer }} \geq Z_{s}^{k=1} \geq Z_{s}^{k=2} \geq Z^{\text {cons }}$ for reservoir Koka and $Z^{\text {buffer }} \leq Z_{s}^{k} \leq Z^{\text {cons }}$ for all other reservoirs. Here, $Z_{s}^{k}$ is a storage control volume for $k=1$ the upper rule curve or $k=2$ the lower rule curve of reservoir Koka. With $k=3$ and $k=4$ the upper rule curves for denoted for reservoirs Kessem and Tendaho respectively. $s=1, \ldots, 12$ enumerates the months of a year. In Eq. (3) the storage control volumes are coded using hyper-parameters $\alpha$. Constraints for the buffer zones $Z^{\text {buffer }}$ and conservation zones $Z^{\text {cons }}$ are given in Table 1. Variable $T$ codes the cyclostationarity and runs from $-\pi$ to $+\pi$ for $s=1, \ldots, 12$. The approach is adopted from Castelletti et al. (2012), who apply artificial neuronal networks for operational rules in a different context. The decision variables sets are evaluated by simulation model OASIS (Hydrologics Inc, 2009), which handles all further constraints like maximum flows and mass conservation. The evolutionary strategy MO-CMA-ES (Igel et al., 2007) was used as multi-objective optimization algorithm in this study. 

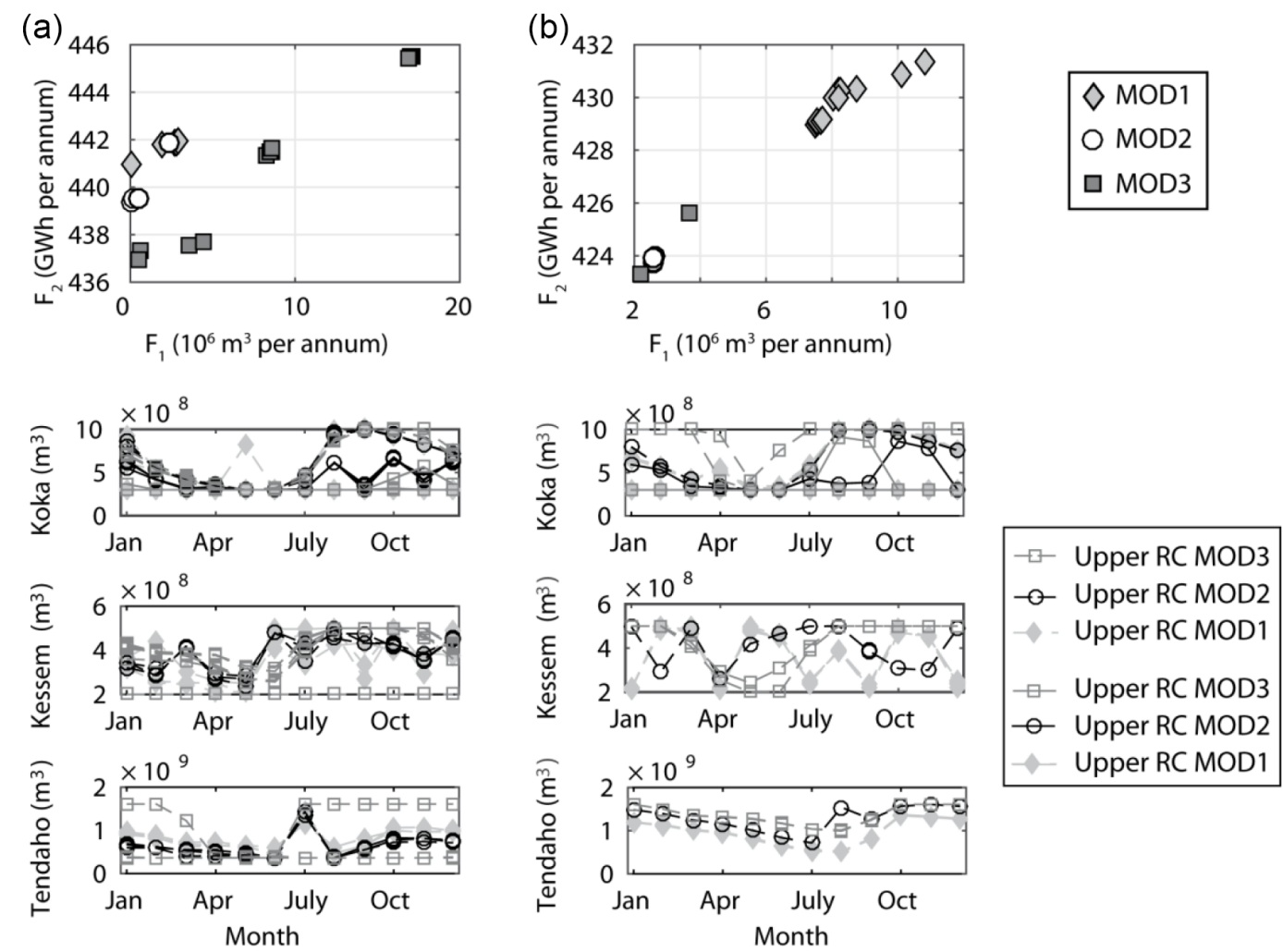

Figure 3. Pareto-Fronts and rule curves (RC) for all solutions from a specific model for (a) recent conditions and (b) the future development plan. Note for (a) and (b) that $F_{1}$ is to be minimized and $F_{2}$ and to be maximized.

\section{Results and discussion}

Optimization runs for the three models where conducted with 60000 model evaluations and a population size of 48 each. The resulting Pareto-Fronts are depicted for recent conditions in Fig. 3a and for the future development plan in Fig. 3b.

With nearly no deficits under recent conditions and $440 \mathrm{GWh}$ per annum energy production, MOD1 performs best when preference is set to minimizing deficits (Objective $F_{1}$ ). The rule curve (RC) behind this solution is unique (Fig. 3a, lower part), because of the size of the conservation zone in May. For the high energy production preference up to $442 \mathrm{GWh}$ per annum, the performance of the reservoir under constant lower (MOD1) and varying lower (MOD2) RCs is similar. The size buffer zone of reservoir Koka is $0 \mathrm{~m}^{3}$ for all solutions of MOD1, MOD2 reserves water for demands especially in January, August, October and December.

For reservoir Tendaho MOD3 proposes a draw down period from March to April and refill in July for low deficits. Surprisingly, RCs for high energy production require an empty reservoir Tendaho.

MOD1 and MOD2 result in lower storages throughout the year and only a major fill in July; this reduces evaporation losses and support from upstream reservoirs. The RCs from all models show the same general course; yet, MOD2 pro- duces the most variable RCs with several draw downs and refills.

Under future development plans no model dominates the others in overall performance, but the models cover different spaces of the Pareto-space. This might be due to the formulation of the RCs or an optimization related problem. In general, deficits under increases demands can be as low as $2 \times 10^{6} \mathrm{~m}^{3}$ when energy production is reduced to $424 \mathrm{GWh}$ per annum. In general, the energy production decreases in average about $3 \%$ under future plans. For reservoir Koka higher storages are proposed from January to April for MOD3. RCs for Kessem reservoir are much smoother for MOD3 in comparison to MOD1. The same shapes of RCs are evident for MOD1 and MOD3, MOD2 proposes an additional refill in August.

\section{Conclusions}

An integrated reservoir management for the multi-reservoir system in the Awash River Basin is needed to maximize socioeconomic benefits. Multi-objective optimization is carried out for conflicting management goals of energy production and basin wide water supply. Future development plans for expansion in irrigation sites are considered. Reservoir performance is assessed by rule curves with a high degree of 
freedom and smooth rule curves, obtained by artificial neuronal networks. For recent conditions the smoothness constraint rule curves cause a performance penalty for the reservoir management. The available water resources in the system are sufficient and a high degree of freedom (non-smooth rule curves) allows for a timely precise allocation. Under the development plans with a higher stress on the system, this cannot be observed. The higher degree of freedom cannot provide any additional performance gains. However, the trade-offs under both scenarios and for all considered models are only huge in terms of deficit, while relative gains in energy performance are negligible. A balanced solution will focus on low deficits and the decision maker may choose his preferred management by special consideration of the underlying rule curves.

It is advised to conduct studies to enhance understanding of Gabeddesa Swamp. Additionally shortcomings in the model, like missing translation times for water routing and irrigation efficiencies need to be addressed.

Acknowledgements. The second author would like to thank the German Academic Exchange Service (DAAD, grant no. A/13/90526) for awarding a scholarship.

\section{References}

Berhe, F. T., Melesse, A. M., Hailu, D., and Sileshi, Y.: MODSIM-based water allocation modelling of Awash River Basin, Ethiopia, Catena, 109, 118-128, doi:10.1016/j.catena.2013.04.007, 2013.

Castelletti, A., Pianosi, F., Quach, X., and Soncini-Sessa, R.: Assessing water reservoirs management and development in Northern Vietnam, Hydrol. Earth Syst. Sci., 16, 189-199, doi:10.5194/hess-16-189-2012, 2012.

Gebretsadik, H. Y.: Simulation Based Optimization for Operation of Multi-Purpose Reservoir System and potential water allocation: Case Study in Awash River Basin Ethiopia, MS thesis, Fakultät Umweltwissenschaften, Technische Universität Dresden, Dresden, Germany, 76 pp., 2015.

Hydrologics Inc: User manual for OASIS with OCL, available at: http://www.hydrologics.net, last access: 12 December 2015, 2009.

Igel, C., Hansen, N., and Roth, S.: Covariance Matrix Adaptation for Multi-objective Optimization, Evol. Comput., 15, 1-28, 2007.

Koutsoyiannis, A. and Economou, D.: Evaluation of the parameterization-simulation-optimization approach for the control of reservoir systems, Water Resour. Res., 39, 1170-1187, doi:10.1029/2003WR002148, 2003.

Labadie, J. W.: MODSIM 8.1: River Basin Management Decision Support System, User Manual and Documentation, Colorado State University, Fort Collins, CO, USA, 2007.

Loucks, D. P., Stedinger, J. R., and Haith, D. A.: Water Resource Systems Planning and Analysis, Prentice-Hall, Englewood Cliffs, N.J., 1981.

Yibeltal, T., Belte, B., Semu, A., Imeru, T., and Yohannes, T.: Coping with water scarcity, the role of agriculture, developing a water audit for Awash river basin, Synthesis report, GCP/INT/072/ITA, Addis Ababa, Ethiopia, 2013 